University of Wollongong

Research Online

Faculty of Engineering and Information

Faculty of Engineering and Information

Sciences - Papers: Part B

Sciences

2019

New technique for strengthening squarereinforced concrete columns by the circularisation with reactive powder concrete and wrapping with fibrereinforced polymer

Atheer Hilal Mahdi Al - Gburi

University of Wollongong, ahmag930@uowmail.edu.au

M Neaz Sheikh

University of Wollongong, msheikh@uow.edu.au

Muhammad N. S Hadi

University of Wollongong, mhadi@uow.edu.au

Follow this and additional works at: https://ro.uow.edu.au/eispapers1

Part of the Engineering Commons, and the Science and Technology Studies Commons

Research Online is the open access institutional repository for the University of Wollongong. For further information contact the UOW Library: research-pubs@uow.edu.au 


\title{
New technique for strengthening squarereinforced concrete columns by the circularisation with reactive powder concrete and wrapping with fibre-reinforced polymer
}

\begin{abstract}
This paper presents a new strengthening technique for square-reinforced concrete (RC) columns by circularisation with reactive powder concrete (RPC) and wrapping with fibre-reinforced polymer (FRP). RC column specimens were tested, divided into four groups of four specimens based on the strengthening technique: four reference square specimens $(150 \mathrm{~mm}$ side length) without any strengthening, four were wrapped with two layers of carbon fibre-reinforced polymer (CFRP) and the remaining eight were strengthened by changing the square cross-section to a $240 \mathrm{~mm}$ diameter circle with RPC jacket. Four of the RPC jacketed specimens were left unwrapped, while the last four were wrapped with two layers of CFRP. From each group, one specimen was tested under concentric axial load, two were tested under eccentric axial load and one was tested under four-point bending. It was found that using the RPC for circularisation and strengthening of existing square RC columns is an effective technique to significantly increase their axial carrying capacity, ultimate flexural load and energy absorption. Wrapping the circularised RC columns with CFRP prevented the failure of the RPC jacket at the corners of the existing square RC columns under the axial load, and improved the ultimate load as well as the energy absorption of the circularised RC columns.
\end{abstract}

\section{Keywords}

wrapping, powder, reactive, circularisation, columns, concrete, squarereinforced, strengthening, technique, fibre-reinforced, polymer

Disciplines

Engineering | Science and Technology Studies

\section{Publication Details}

Algburi, A. H. M., Sheikh, M. Neaz. \& Hadi, M. N. S. (2019). New technique for strengthening squarereinforced concrete columns by the circularisation with reactive powder concrete and wrapping with fibre-reinforced polymer. Structure and Infrastructure Engineering: maintenance, management, lifecycle design and performance, 15 (10), 1392-1403. 


\title{
New Technique for Strengthening Square Reinforced Concrete Columns by the Circularisation with Reactive Powder Concrete and Wrapping with Fibre Reinforced Polymer
}

Atheer H.M. Algburi ${ }^{1}$

${ }^{1}$ Ph.D. Candidate, School of Civil, Mining and Environmental Engineering, University of Wollongong, NSW 2522, Australia. E-mail: ahmag930@uowmail.edu.au

M. Neaz Sheikh ${ }^{2}$

${ }^{2}$ Associate Professor, School of Civil, Mining and Environmental Engineering, University of Wollongong, NSW 2522, Australia.E-mail: msheikh@uow.edu.au

Muhammad N.S. Hadi ${ }^{3 *}$, F.ASCE

${ }^{3}$ Associate Professor, School of Civil, Mining and Environmental Engineering, University of Wollongong, NSW 2522, Australia, *Corresponding Author. Email: mhadi@uow.edu.au. Tel.: +61 2 4221 4762; Fax: +61242213238.

\begin{abstract}
This paper presents a new strengthening technique for square reinforced concrete (RC) columns by the circularisation with reactive powder concrete (RPC) and wrapping with fibre reinforced polymer (FRP). Results of testing $16 \mathrm{RC}$ column specimens are presented. The specimens were divided into four groups of four specimens based on the strengthening techniques. Four specimens were considered as reference square (150 mm side length) RC specimens without any strengthening, four specimens were wrapped with two layers of carbon fibre reinforced polymer (CFRP) and the remaining eight specimens were strengthened by circularisation them (changing the square crosssection to a $240 \mathrm{~mm}$ diameter circle) with RPC jacket. Four of the RPC jacketed specimens were left unwrapped while the last four specimens were wrapped with two layers of CFRP. From each group, one specimen was tested under concentric axial load, two specimens were tested under eccentric axial load and one specimen was tested under four-point bending. It was found that using the RPC for
\end{abstract}


circularisation and strengthening existing square RC columns is an effective technique to significantly increase their axial carrying capacity, ultimate flexural load and energy absorption. Wrapping the circularised RC columns with CFRP prevented the failure of the RPC jacket at the corners of the existing square RC columns under the axial load, and improved the ultimate load as well as the energy absorption of the circularised RC columns.

Keywords: Square Concrete Column; Reactive Powder Concrete; Jacketing; CFRP; Wrapping.

\section{Introduction}

The common reasons for retrofitting reinforced concrete $(\mathrm{RC})$ columns in vital infrastructure include functional changes, corrosion of steel reinforcement and changes in design code requirements. In recent years, many techniques were used for strengthening RC columns (Wu, Liu, \& Oehlers, 2006). Reinforced concrete with compressive strength less than $50 \mathrm{MPa}$ (NS-RC) was used as a jacket to strengthen square RC columns. The jacket was reinforced with either steel bars or mesh and had a thickness of not less than 100 mm (Rodriguez and Park, 1991; Sezen and Miller, 2011). However, NS-RC jacketing may not be a very efficient method to strengthen square RC column, as the NS-RC jacket increases substantially the self-weight of the existing column and reduces the available space in the strengthened structure. Also, the distribution and the connection of the added reinforcement of the jacket are among the practical disadvantages of NS-RC jacketing. In other words, the anchoring of the added longitudinal steel bars with the foundation and the connection of the lateral steel reinforcement with the existing column create difficulties during the construction of the NS-RC jacket (Julio, Branco, \& Silva, 2003; Waghmare, 2011).

Takeuti, Hanai, and Mirmiran (2008) used high strength reinforced concrete (HS-RC) jackets to strengthen RC columns. These jackets had smaller thickness compared with the NS-RC jackets. However, the RC column strengthened with HS-RC jacket usually exhibits a quasi-linear behaviour up to the ultimate axial load. After the ultimate axial load, the axial capacity of HS-RC jacketed 
column drops significantly (Campione, Fossetti, Giacchino, \& Minafo, 2014). The main reason for this behaviour of HS-RC jacketed columns is the tensile stresses developed by the different lateral expansion rates of the NS-RC core and the HS-RC jacket, which lead to a premature failure in the jacket (Minafo and Papia, 2016). Moreover, the HS-RC jacketing has similar practical disadvantages to the NS-RC jacketing which are mainly due to the reinforcement of the jacket.

Fibre reinforced polymer (FRP) jacket and steel jacket were used for strengthening RC columns (Sezen and Miller, 2011). However, the steel jacket suffers from poor corrosion resistance as well as local buckling during the construction process and service life. Compared to the steel jacket, the FRP jacket possesses lighter self-weight and superior durability. The FRP jacket increases the strength and ductility of the RC columns (Karbhari and Gao, 1997). Nevertheless, strengthening by FRP jacket depends mainly on the lateral confinement pressure (Wu, Liu, \& Oehlers, 2006). Although circular FRP jackets provide uniform confinement pressure to the concrete, square and rectangular FRP jackets provide nonuniform confinement pressure to the concrete. The nonuniform confinement pressure decreases the confinement efficiency of the FRP jacket (Lam and Teng, 2003). Rounding the corners of the section and shape modification are commonly used techniques to improve the efficiency of the confinement for the square and rectangular columns. The radius of rounding the corners of the existing square and rectangular RC columns is dominated by the presence of internal lateral steel reinforcement and the requirement of the concrete cover for the durability of the column (Yan and Pantelides, 2011). Thus, shape modification of square columns to circular columns is considered an effective technique for improving the efficiency of the confinement for square columns (Hadi, Pham, \& Lei, 2013).

It is well known that FRP wrapping has a marginal positive effect on the yield load and flexural capacity of RC columns (Bank, 2006). Also, the confinement efficiency of FRP decreases for columns with large sizes (Lam and Teng, 2003). Furthermore, confinement efficiency decreases under eccentric axial loading conditions (Hadi, 2009; Hadi, Pham, \& Lei, 2013). 
Therefore, several layers of FRP may be required to achieve a significant enhancement in the axial strength of RC columns with large sizes which are subjected to an eccentric axial load. The increase of FRP layers is an expensive solution and leads to bond failure (ACI 440.2R, 2017).

Reactive powder concrete (RPC) is a high-performance concrete with superior mechanical properties, ductility, repairing characteristics and durability compared to the other types of concrete (Richard and Cheyrezy 1995; Lee, Wang, \& Chiu, 2007; Chang, Chen, Wang, \& Wu, 2009). The dense structure of the RPC and the presence of the steel fibres reduce the differential tensile strains in the RPC and increase the load carrying capacity (Richard and Cheyrezy 1995; Malik and Foster 2010). Malik and Foster (2010) studied the experimental behaviour of FRP confined circular RPC column specimens. The RPC column specimens were internally reinforced with steel fibre without any steel bars and externally wrapped with carbon fibre reinforced polymer (CFRP). Malik and Foster (2010) found that the CFRP confined RPC column specimen achieved 19\% greater maximum axial load than unconfined RPC column specimen. Huynh, Foster, Valipour, and Randall (2015) studied the behaviour of square RC specimens constructed with high strength concrete partially replaced by RPC under three-point bending. The study showed that the partial replacement of the high strength concrete by the RPC improved the maximum load and energy absorption of the tested specimens. The RPC can be used for strengthening existing deficient RC columns as it has superior durability and superior mechanical properties. However, the behaviour of square RC columns strengthened by the circularisation with RPC jacket has not been investigated yet. Also, the behaviour of square RC columns strengthened by the circularisation with RPC jacket and wrapped with FRP has not been investigated either.

This paper proposes a new strengthening technique for square RC columns consisting of circularisation with RPC and wrapping with FRP. The column specimens in this study were tested under different loading conditions so as to establish the experimental axial load-bending moment interaction diagrams. The loading conditions included concentric axial load, eccentric axial loads and four-point bending. 


\section{Experimental program}

\subsection{Specimen details}

In this study, 16 reinforced concrete (RC) specimens were cast and tested. The specimens were divided into four groups of four specimens based on the adopted strengthening technique (Figure 1). The base specimens were assumed to be the existing RC columns with a square cross-section of 150 $\mathrm{mm} \times 150 \mathrm{~mm}$ and a height of $800 \mathrm{~mm}$. The base specimens are considered as short columns based on AS 36000 (2009) (both ends pinned unbraced column with effective length to the radius of gyration ratio $\leq 22$ ). All the base specimens were cast with normal strength concrete (NSC). The NSC was supplied by a local company with a target compressive strength of $25 \mathrm{MPa}$. Each of the base specimens was reinforced with 4N12 (4 steel bars of $12 \mathrm{~mm}$ diameter) deformed longitudinal steel bars and R6 (6 mm diameter) plain steel ties spaced at $50 \mathrm{~mm}$ centre to centre. A clear concrete cover of $15 \mathrm{~mm}$ was provided at the sides as well as at the top and bottom of the base specimens. The clear concrete cover of the base specimens was taken to be more than $4 / 3$ times the maximum size of the coarse aggregate for the NSC. In this study, the maximum size of the coarse aggregate for the NSC was $10 \mathrm{~mm}$. The specimens in the first group were the reference base specimens without any strengthening and were identified as Group S specimens. The specimens in the second group were rounded at the corners for a radius of $20 \mathrm{~mm}$. These were wrapped with two layers of CFRP and were identified as Group SF specimens. The specimens in the third group were circularised with RPC jacket. The outer diameter of the RPC jacket was $240 \mathrm{~mm}$. These were identified as Group SJ specimens. The specimens in the fourth group were circularised with RPC jacket of $240 \mathrm{~mm}$ outer diameter and wrapped with two layers of CFRP. These were identified as Group SJF specimens.

In each group of specimens, one specimen was tested under concentric axial load, one specimen was tested under $20 \mathrm{~mm}$ eccentric axial load, one specimen was tested under $40 \mathrm{~mm}$ eccentric axial load and the remaining specimen was tested under four-point bending. The tested specimens were labelled based on the group name and the loading condition (Table 1). The first part of the specimen label denotes the group name and the second part denotes the loading condition. For example, SF-40 
refers to the specimen that was wrapped with two layers of CFRP and tested under axial load with 40 mm eccentricity. Specimen SJF-B refers to the RPC jacketed specimen wrapped with two layers of CFRP and tested under four-point bending. The test matrix with full details of the specimens is presented in Table 1.

\subsection{Components and mix design of RPC}

The RPC mix used in this study contains cement, silica fume, fine sand, superplasticiser, water and steel fibre. The cement used in the RPC mix was General purpose cement (Type GP) according to AS 3972 (2010). The silica fume was densified silica fume produced by SIMCOA's silicon plant, Western Australia (SIMCOA, 2018), and was supplied by the Australasian (iron \& steel) Slag Association (ASA, 2018). The sand was Sydney fine sand with 150-600 $\mu \mathrm{m}$ particle size. The Master Glenium SKY 8700 was used as superplasticiser (BASF, 2018). The water used in the RPC mix was tap water available in the laboratory. The steel fibres used in the RPC mix were straight and smooth steel fibres with a length of $13 \mathrm{~mm}$, a diameter of $0.2 \mathrm{~mm}$ and a nominal tensile strength of $2500 \mathrm{MPa}$ (Steel Wire Fibres, 2018).

The mix design of the RPC consisted of $880 \mathrm{~kg} / \mathrm{m}^{3}$ cement, $220 \mathrm{~kg} / \mathrm{m}^{3}$ silica fume, $924 \mathrm{~kg} / \mathrm{m}^{3}$ Sydney fine sand, $50.16 \mathrm{l} / \mathrm{m}^{3}$ superplasticiser, $176 \mathrm{~kg} / \mathrm{m}^{3}$ water and $117 \mathrm{~kg} / \mathrm{m}^{3}$ steel fibres. The proportion of steel fibre was $1.5 \%$ by volume of the RPC. The proportion of steel fibre was selected based on the recommendations in Ju, Jia, Liu, and Chen (2007). It was found that steel fibre content of $1.5 \%$ by volume increased the compressive strength and tensile strength of the RPC (Ju, Jia, Liu, \& Chen, 2007). The RPC mix was designed to achieve high flowability and high compressive strength. All the experimental work of this study was carried out at the Structural Engineering Laboratory of the University of Wollongong, Australia.

\subsection{Preliminary tests}

Flowability of the RPC was evaluated by applying the flow table test according to the ASTM C230/C230M (2014). The RPC mix achieved high flowability with an average flow diameter of 220 
$\mathrm{mm}$. Compressive strength and indirect tensile strength of NSC and RPC were determined according to AS 1012.9 (2014) and AS 1012.10 (2014), respectively. Each test was performed using three cylinder specimens of $100 \mathrm{~mm}$ diameter and $200 \mathrm{~mm}$ height. The average 28-day compressive strength and the average 28-day splitting tensile strength of the NSC were $29 \mathrm{MPa}$ and $2.5 \mathrm{MPa}$, respectively. The average compressive strengths of the NSC were $37 \mathrm{MPa}$ and $39 \mathrm{MPa}$ at the start and the end of the test, respectively. The RPC had an average compressive strength of $110 \mathrm{MPa}$ and an average splitting tensile strength of $9 \mathrm{MPa}$ at 28 days. The average compressive strength of the RPC was $124 \mathrm{MPa}$ at the start of the test and $129 \mathrm{MPa}$ at the end of the test.

Reinforcing steel bars of the base specimens were tested according to AS 1391 (2007) to determine the tensile strength. The test was carried out using the $500 \mathrm{kN}$ Instron 8033 testing machine. The tensile strength test was performed by testing three specimens from each bar size. The N12 bars had an average yield tensile strength of $585 \mathrm{MPa}$ and an average ultimate tensile strength of $634 \mathrm{MPa}$. The R6 bars had an average yield tensile strength of $578 \mathrm{MPa}$ and an average ultimate tensile strength of $613 \mathrm{MPa}$. The CFRP sheets used for wrapping of the specimens had a width of $100 \mathrm{~mm}$ and an average thickness of $0.3 \mathrm{~mm}$. Coupon test according to the ASTM D3039 (2008) was performed to determine the tensile strength of the CFRP. Three specimens with a width of $25 \mathrm{~mm}$ and a length of $250 \mathrm{~mm}$ were tested. The tensile strength test of the CFRP was performed using the $500 \mathrm{kN}$ capacity Instron 8033 testing machine. For two layers of the CFRP sheets, the average maximum tensile force per unit width was $1249 \mathrm{~N} / \mathrm{mm}$. The average ultimate tensile strain and the average tensile modulus of elasticity were 0.0247 and $50567 \mathrm{~N} / \mathrm{mm}$, respectively.

\subsection{Fabrication of test specimens}

Plywood formwork was used for the base specimens with clear interior dimensions of $150 \mathrm{~mm} \times 150$ $\mathrm{mm} \times 800 \mathrm{~mm}$. The rounded corners of the specimens of Group SF were formed by using Styrofoam strips, which were fixed at the inside corners of the formwork. The reinforcement cages were formed by connecting the R6 steel ties with the longitudinal N12 steel bars. The entire reinforcement cages were placed inside the formwork before casting of the concrete. All base specimens were cast with 
NSC. Two electric vibrators with a $25 \mathrm{~mm}$ diameter hose were used to compact the NSC inside the formwork. The base specimens were cured under the laboratory conditions for 24 hours. The specimens were covered with a wet hessian for six days. The base specimens were demoulded after seven days of wet curing and left to cure under the laboratory conditions until the age of 26 days. At the age of 26 days, the RPC jackets were cast for eight base specimens (Groups SJ and SJF), whereas the remaining eight specimens were left without jacketing (Groups S and SF). The four unjacketed specimens with rounded corners were wrapped with two layers of CFRP (Groups SF). The remaining four base specimens were left without any strengthening and considered as reference specimens (Group S).

To achieve adequate bond strength between the surface of the base specimen and the RPC jacket, adequate care was taken to achieve the desired roughness for the surface of the base specimen. First, the surface of each base specimen was sandblasted inside a closed sandblasting chamber. Then, a chipping hammer was used to prickle the zones of the base specimen that were not sandblasted efficiently. Next, all weak particles on the surface of the base specimens were removed by using a steel wire brush. Afterwards, air jet was applied by a blower to clean the dust on the surface. In the end, the surface of the base specimen was cleaned with a wet piece of cloth and left to dry in the laboratory until the day of the RPC casting.

The PVC pipes were used for the formworks of the RPC jackets of Group SJ and SJF specimens. Each PVC pipe had a clear interior diameter of $240 \mathrm{~mm}$. Hence, the clear thickness of the RPC jacket at the corners of the base specimen was $14 \mathrm{~mm}$. The height of the formworks of the jacketed specimen was $800 \mathrm{~mm}$. The eight base specimens were placed first on a plywood base at the correct positions then the PVC pipe formworks were installed and glued to the base by silicon glue. Later, the PVC pipe formwork was supported by three plywood frames one at the top, one at the mid-height and one at the bottom. The jackets were cast with the RPC. Two small electric vibrators were used to compact the RPC inside the PVC pipe formwork. The RPC passed through the narrow formwork of the jacket easily due to its high flowability. Figure 2 shows the preparation of specimens before and after 
jacketing. The RPC jacketed specimens were cured for 24 hours then covered with wet hessian for six days. On the seventh day, the RPC jacketed specimens were demoulded and the surfaces of the four specimens that were designed to be wrapped (Group SJF) were cleaned and left to dry before wrapping with CFRP.

The wet layup method was used for wrapping the specimens of Groups SF and SJF with CFRP. The CFRP sheets were cut to achieve the length of two layers plus a $100 \mathrm{~mm}$ of circumferential overlap. Afterwards, each sheet was coated with epoxy resin on the two sides. The surface of the specimen was also coated with epoxy resin. To prepare the epoxy resin, the hardener and epoxy were mixed with a ratio of 1 to 5 by volume. The coated CFRP sheet was wrapped gently on the surface of the specimen. A very thin layer of epoxy resin was applied on the surface of the CFRP sheet at the overlap zone. This technique was adopted to avoid any de-bonding between the CFRP layers. Group SF and SJF specimens were wrapped with two layers of CFRP for the entire height of the specimen.

To prevent any premature failure during the test, the specimens tested under concentric and eccentric axial loads were wrapped at both ends with two layers of CFRP with a width of $100 \mathrm{~mm}$. Also, the four specimens tested under four-point bending were wrapped with two layers of CFRP from each end up to the middle one-third of the specimens (up to the pure bending moment zone). This was done to avoid any shear failure for Specimen SJ-B. Specimens S-B, SF-B and SJF-B were wrapped with two layers of CFRP from each end as was done to Specimen SJ-B. This additional CFRP wrapping was done to achieve consistent comparison between the test specimens. After wrapping, the specimens were cured in the laboratory for at least seven days before the test.

\subsection{Testing of the specimens}

All specimens were tested using the Denison testing machine of $5000 \mathrm{kN}$ capacity. Deformation control at a rate of $0.5 \mathrm{~mm}$ per minute was used for testing. The axial deformation was determined by the average reading of two Linear Variable Differential Transducers (LVDTs). The LVDTs were connected to the lower plate of the testing machine and attached vertically to the upper plate of the 
testing machine at two opposite corners. The axial load was directly captured from the load cell of the Denison testing machine. In addition, a laser triangulation was used to record the mid-height lateral deformation of the eccentrically loaded specimens and the midspan deflection of the specimens tested under four-point bending. Loading heads similar to those used by Hadi, Khan, and Sheikh (2016) were used in this study to apply the eccentric axial load. Each loading head consisted of an adapter steel plate with two grooves. The steel loading heads were installed at the ends of the specimen using high strength plaster and left to dry for about one hour before the start of the test. To apply the eccentric axial load, two steel plates with overhang edge were placed in the required grooves at the top and bottom to achieve the required eccentricity (20 $\mathrm{mm}$ or $40 \mathrm{~mm}$ ). Figure 3 shows the test setup of the eccentrically loaded specimen. Steel frames, similar to those used by Hadi, Mai, and Sheikh (2018) with flat and circular supports, were used for the four-point bending test. The steel frames consisted of two steel rigs fixed at the top and bottom of the specimen to achieve the fourpoint bending system with a shear span of $233 \mathrm{~mm}$ (one-third of the span length).

\section{Test results and discussion}

\subsection{Definition of energy absorption}

Energy absorption of each specimen was computed by calculating the area under the loaddeformation curve. For the specimens tested under concentric and eccentric axial loads, the energy absorption was calculated for up to three times the deformation at the yield load $\left(3 \delta_{\mathrm{y}}\right)$ (ASTM C1018, 1997). The energy absorption up to $3 \delta_{\mathrm{y}}$ was not considered representative of the energy absorption of the specimens tested under four-point bending. This is because the $3 \delta_{\mathrm{y}}$ for Specimens S-B, SF-B and SJF-B was lower than the deflection corresponding to the maximum flexural load. Therefore, the energy absorption of the specimens tested under four-point bending was computed using the area under the load-deflection curve for up to $5.5 \delta_{\mathrm{y}}\left(\mathrm{ASTM}\right.$ C1018, 1997). The $\delta_{\mathrm{y}}$, which is the deformation at the yield load, was determined by the intersection of two straight lines. The first straight line is the 
best-fit regression line to the initial part of the load-deformation response and the second straight line is a horizontal line passing through the maximum load (Hadi, Khan, \& Sheikh, 2016).

\subsection{Behaviour of the specimens under concentric axial load}

Figure 4 shows the failure modes of the specimens tested under concentric axial load. Specimen S-0 failed by the spalling of concrete cover close to the corners at the mid-height segment of the specimen. Spalling of concrete cover occurred probably because of the stress concentrations at the corners of the base specimen. Later, cracks at different positions of the specimen were observed. The final failure of Specimen S-0 occurred by the buckling of the longitudinal steel bars and fracture of transverse steel ties. Failure of Specimen SF-0 occurred by the rupture of the CFRP and the crushing of concrete at the mid-height segment of the specimen. Specimen SJ-0 failed by splitting vertical cracks close to the corners of the base specimen followed by small cracks at different parts of the specimen. The vertical cracks occurred as a result of the stress concentrations at the corners of the base specimen. Failure of Specimen SJF-0 occurred by the CFRP rupture and RPC crushing at the mid-height of the specimen (Figure 4).

The axial load-axial deformation curves of the reference specimen and the strengthened specimens under concentric axial load are shown in Figure 5. Specimen S-0 achieved a yield axial load of 666 $\mathrm{kN}$ with a corresponding yield axial deformation of $2.2 \mathrm{~mm}$. The specimen achieved an ultimate axial load of 798 kN. The energy absorption of Specimen S-0 was 4000 kN.mm (Table 2).

Axial load-axial deformation response of Specimen SF-0 was characterized by a quasi-bilinear behaviour. After the yield axial load, the axial load increased with the increase in the axial deformation (hardening response) up to the ultimate axial load. The failure of Specimen SF-0 occurred suddenly at an ultimate axial load of $1462 \mathrm{kN}$. The yield axial load of Specimen SF-0 was $28 \%$ higher than the yield axial load of Specimen S-0, and the ultimate axial load of Specimen SF-0 was $83 \%$ higher than the ultimate axial load of Specimen S-0. The energy absorption of Specimen SF-0 was $158 \%$ higher than the energy absorption of Specimen S-0 (Table 2). The higher ultimate 
axial load and energy absorption of Specimen SF-0 compared to Specimen S-0 resulted from the confinement of CFRP wrapping.

The initial axial stiffness of Specimen SJ-0 was greater than the initial axial stiffness of Specimens S-0 and SF-0 (Figure 5). The higher initial axial stiffness of Specimen SJ-0 compared to the initial axial stiffness of Specimens S-0 and SF-0 was due to the jacketing with the RPC. The yield axial load of Specimen SJ-0 was $2652 \mathrm{kN}$. Specimen SJ-0 sustained an ultimate axial load of $2892 \mathrm{kN}$, which was $9 \%$ higher than the yield axial load. After the ultimate axial load, the axial load of Specimen SJ-0 dropped suddenly with increasing axial deformation. The increase in the axial deformation was due to the marginal confinement provided by the RPC jacket on the base specimen. The sudden drop in the axial load decreased the axial load to about $45 \%$ of the ultimate axial load. Afterwards, the axial load-axial deformation response exhibited softening response (decrease in the axial load with the increase in the axial deformation). The softening response was due to the confinement provided by the internal steel ties. It is noted that Specimen SJ-0 did not lose the structural integrity even at the end of the test. Specimen SJ-0 achieved substantially larger yield and ultimate axial loads compared to Specimen S-0. The yield axial load of Specimen SJ-0 was 298\% greater than the yield axial load of Specimen S-0, and the ultimate axial load of Specimen SJ-0 was $262 \%$ greater than the ultimate axial load of Specimen S-0. Also, the energy absorption of Specimen SJ-0 was $239 \%$ greater than the energy absorption of Specimen S-0 (Table 2). The increase in the yield and ultimate axial loads and energy absorption of Specimen SJ-0 resulted from the increase in the axial stiffness of the specimen due to the circularisation of the base specimen by the RPC jacket.

Specimen SJF-0 sustained a yield axial load of 3018 kN. The ultimate axial load of Specimen SJF0 was $21 \%$ higher than the yield axial load. The higher ultimate axial load of Specimen SJF-0 compared to the yield axial load was due to the influence of the confinement provided by the CFRP wrapping on the jacketed specimen. The ultimate axial load of Specimen SJF-0 was followed by a sudden drop in the axial load, which was due to the rupture of CFRP. Afterwards, there was an increase in the axial load up to a second peak axial load (Figure 5). The second peak axial load was 
about $10 \%$ less than the first peak axial load (ultimate axial load). The second peak axial load was due to the effect of confinement provided by the RPC jacket to the base specimen. Later, a second drop in the axial load occurred and the axial load decreased to about $30 \%$ of the ultimate axial load, which was due to the crushing of the RPC jacket. The yield axial load of Specimen SJF-0 was 353\% greater than the yield axial load of Specimen S-0, and the ultimate axial load of Specimen SJF-0 was $356 \%$ greater than the ultimate axial load of Specimen S-0. The energy absorption of Specimen SJF0 was $467 \%$ greater than the energy absorption of Specimen S-0 (Table 2). In addition, the ultimate axial load of Specimen SJF-0 was $26 \%$ larger than the ultimate axial load of Specimen SJ-0. The energy absorption of Specimen SJF-0 was $67 \%$ greater than the energy absorption of Specimen SJ-0. The higher ultimate axial load and energy absorption of Specimen SJF-0 compared to Specimen SJ0 can be attributed to the influence of the confinement provided by the CFRP wrapping.

It can be observed that Specimen SJ-0 had higher yield axial load, ultimate axial load and energy absorption compared to Specimen SF-0. Also, Specimen SJF-0 achieved higher yield and ultimate axial loads as well as higher energy absorption than Specimen SJ-0. It is important to note that wrapping the RPC jacket with CFRP in case of Specimen SJF-0 limited the lateral expansion at the corners of the base specimen and hence prevented the premature lateral tensile failure in the RPC jacket that occurred in Specimen SJ-0.

To show the increase in the maximum axial stress of the specimens due to the increase in the axial stiffness and the confinement of CFRP, the axial stress-axial strain responses of Specimens S-0, SF0, SJ-0 and SJF-0 were presented in Figure 6. As can be seen in Figure 6, the initial axial stiffness of Specimen SF-0 was relatively identical to the initial axial stiffness of Specimen S-0. The maximum axial stress of Specimen SF-0 was $83 \%$ higher than the maximum axial stress of Specimen S-0. The initial axial stiffness of Specimen SJ-0 was significantly higher than the initial axial stiffness of Specimen S-0. The maximum axial stress of Specimen SJ-0 was $80 \%$ higher than the maximum axial stress of Specimen S-0. Specimens SJF-0 had an initial axial stiffness close to the initial axial stiffness of Specimen SJ-0. However, Specimen SJF-0 achieved maximum axial stress $127 \%$ higher than the 
maximum axial stress of Specimen S-0. It is evident that the proposed strengthening technique of this study depends on the increase in the stiffness of the square RC column due to the circularisation with RPC, then wrapping with CFRP to achieve the required energy absorption.

\subsection{Behaviour of the specimens under $20 \mathrm{~mm}$ eccentric axial load}

Specimen S-20 failed by the crushing of concrete on the compression side at the mid-height segment of the specimen with cracking of concrete cover on the tension side (Figure 7(a)). Failure of Specimen SF-20 initiated with outward buckling and cracking on the tension side followed by the rupture of the CFRP on the compression side. Failure of Specimen SJ-20 initiated with splitting vertical cracks on the compression side close to the corners of the base specimen followed by the cracking of RPC on the tension side. Specimen SJF-20 failed by the rupture of the CFRP with crushing of RPC on the compression side within the mid-height segment of the specimen, which was followed by cracking between the CFRP strips on the tension side within the mid-height segment of the specimen (Figure $7(\mathrm{a}))$

Figure 8(a) shows the axial load-axial deformation responses of the specimens tested under $20 \mathrm{~mm}$ eccentric axial load. The yield axial load and corresponding axial deformation of Specimen S-20 were $397 \mathrm{kN}$ and $2.3 \mathrm{~mm}$, respectively. The specimen achieved an ultimate axial load of $418 \mathrm{kN}$ followed by a softening response up to the end of the test. The energy absorption of Specimen S-20 was 2207 kN.mm (Table 3).

Under $20 \mathrm{~mm}$ eccentric axial load, the initial slope of the axial load-axial deformation response of Specimen SF-20 was identical to the initial slope of Specimen S-20. This is because wrapping with CFRP did not influence the initial stiffness of the column. The ultimate axial load of Specimen SF20 was slightly higher than the yield axial load. However, the axial deformation corresponding to the ultimate axial load was significantly higher than the yield axial deformation. This response was due to the effect of the confinement provided by the CFRP. Beyond the ultimate axial load, the axial load decreased with increasing axial deformation up to the final failure. The final failure occurred by the 
rupture of the CFRP. The yield axial load of Specimen SF-20 was $49 \%$ higher than the yield axial load of Specimen S-20, and the ultimate axial load of Specimen SF-20 was 55\% higher than the ultimate axial load of Specimen S-20. The energy absorption of Specimen SF-20 was 139\% higher than the energy absorption of Specimen S-20 (Table 3).

The axial load-axial deformation of Specimen SJ-20 showed a quasi-linear response up to the yield axial load. The yield axial load of Specimen SJ-20 was calculated as $1915 \mathrm{kN}$. The ultimate axial load of Specimen SJ-20 was only 7\% higher than the yield axial load. After the ultimate axial load, the axial load of Specimen SJ-20 dropped to about $45 \%$ of the ultimate axial load due to the splitting of the RPC jacket on the compressive side of the specimen. Afterwards, the axial load decreased with increasing axial deformation at a slower rate, which was due to the confinement provided by the internal steel ties. The yield axial load of Specimen SJ-20 was 382\% larger than the yield axial load of Specimen S-20, and the ultimate axial load of Specimen SJ-20 was 391\% larger than the ultimate axial load of Specimen S-20. The energy absorption of Specimen SJ-20 was $270 \%$ larger than the energy absorption of Specimen S-20 (Table 3).

Specimen SJF-20 achieved a yield axial load of $2227 \mathrm{kN}$ and an ultimate axial load of $2398 \mathrm{kN}$. After the ultimate axial load, the axial load of Specimen SJF-20 dropped slightly and increased again to about $98 \%$ of the ultimate axial load. After that, the axial load decreased suddenly with increasing axial deformation to about $49 \%$ of the ultimate axial load. Later, the specimen showed a softening response up to the end of the test. Compared to Specimens SF-20 and SJ-20, Specimen SJF-20 achieved higher yield and ultimate axial loads as well as higher energy absorption. The yield axial load of Specimen SJF-20 was $461 \%$ greater than the yield axial load of Specimen S-20, and the ultimate axial load of Specimen SJF-20 was $473 \%$ greater than the ultimate axial load of Specimen S-20. The energy absorption of Specimen SJF-20 was $763 \%$ greater than the energy absorption of Specimen S-20 (Table 3). 


\subsection{Behaviour of the specimens under $40 \mathrm{~mm}$ eccentric axial load}

The failure of Specimen S-40 started by concrete crushing on the compression side with concrete cracking on the tension side close to the mid-height segment of the specimen. Then, the crushing of concrete increased until the concrete on the compression side of the specimen was fragmented (Figure 7(b)). Specimen SF-40 failed initially by tensile cracks between the CFRP strips at the mid-height segment of the specimen followed by the rupture of the CFRP on the compression side. Failure of Specimen SJ-40 initiated with tensile cracks at the upper one-third segment of the specimen followed by inclined and vertical splitting cracks on the compression side. Specimen SJF-40 failed by typical tensile-flexural cracks between the CFRP strips on the tension side with clear outward buckling at the mid-height of the specimen, which was followed by rupture of the CFRP and crushing of the RPC on the compression side (Figure 7(b)).

Figure 8(b) compares the axial load-axial deformation responses of the specimens tested under 40 mm eccentric axial load. The yield axial load of Specimen S-40 was $297 \mathrm{kN}$ with a corresponding axial deformation of $2.7 \mathrm{~mm}$. The ultimate axial load of Specimen S-40 was $329 \mathrm{kN}$. After the ultimate axial load, Specimen S-40 showed softening axial load-axial deformation response with the energy absorption of 2125 kN.mm (Table 3).

The initial axial load-axial deformation response of Specimen SF-40 was similar to the initial axial load-axial deformation of Specimen S-40. However, the yield axial load of Specimen SF-40 was 22\% higher than the yield axial load of Specimen S-40, and the ultimate axial load of Specimen SF-40 was $30 \%$ higher than the ultimate axial load of Specimen S-40. The energy absorption of Specimen SF40 was $38 \%$ higher than the energy absorption of Specimen S-40 (Table 3). The higher ultimate axial load and energy absorption of Specimen SF-40 can be attributed to the confinement provided by the CFRP.

Under eccentric axial load with $40 \mathrm{~mm}$ eccentricity, Specimen SJ-40 achieved higher initial stiffness than Specimen S-40. The higher initial stiffness of Specimen SJ-40 compared to that of 
Specimen S-40 was due to the circularisation of the cross-section by the RPC jacket. The yield axial load of Specimen SJ-40 was $1462 \mathrm{kN}$. Specimen SJ-40 sustained an ultimate axial load of $1549 \mathrm{kN}$. Afterwards, the axial load dropped to about $37 \%$ of the ultimate axial load with a slight increase in the axial deformation. Later, the axial load-axial deformation behaviour demonstrated softening response due to the confinement provided by the internal steel ties. A significant improvement in the axial strength was achieved by Specimen SJ-40 compared to that of Specimen SF-40. The yield axial load of Specimen SJ-40 was 392\% greater than the yield axial load of Specimen S-40, and the ultimate axial load was $370 \%$ greater than the ultimate axial load of Specimen S-40. The energy absorption of Specimen SJ-40 was 164\% greater than the energy absorption of Specimen S-40 (Table 3). The higher yield axial load, ultimate axial load and energy absorption of Specimen SJ-40 are attributed to the influence of the RPC jacket.

The initial slope of the axial load-axial deformation curve of Specimen SJF-40 was similar to the initial slope of axial load-axial deformation curve of Specimen SJ-40 up to the yield axial load, as the initial stiffness of both specimens was identical and did not change by CFRP wrapping. Specimen SJF-40 achieved an ultimate axial load of $1814 \mathrm{kN}$, which was $9 \%$ higher than the yield axial load. After the ultimate axial load, the axial load-axial deformation curve of Specimen SJF-40 slightly fluctuated, then the axial load dropped to about $47 \%$ of the ultimate axial load. Afterwards, the specimen exhibited a gradual softening response up to the end of the test. As can be seen in Table 3, Specimen SJF-40 had greater yield axial load, ultimate axial load, and energy absorption than Specimen SJ-40. The yield axial load of Specimen SJF-40 was $462 \%$ greater than the yield axial load of Specimen S-40, and the ultimate axial load of Specimen SJF-40 was $451 \%$ greater than the ultimate axial load of Specimen S-40. The energy absorption of Specimen SJF-40 was $577 \%$ greater than the energy absorption of Specimen S-40.

It is important to note that the slenderness ratio (effective length to the radius of gyration) of Specimens SJ-20, SJF-20, SJ-40 and SJF-40 was less than the slenderness ratio of Specimens S-20, SF-20, S-40 and SF-40. This provided more resistance against buckling for Specimens SJ-20, SJF- 
20, SJ-40 and SJF-40 compared to Specimens S-20, SF-20, S-40 and SF-40. Also, the eccentricity to diameter ratio for Specimens SJ-20, SJF-20, SJ-40 and SJF-40 was less than the eccentricity to side length ratio for Specimens S-20, SF-20, S-40 and SF-40. However, the eccentricity for all the specimens was measured from the centre-line of the cross-section of the base square RC column specimens. Furthermore, the eccentricity for all the specimens was within the cross-section of the base square RC column specimens. This achieved consistency in the test of the specimens in Groups S and SF with test of the specimens in Groups SJ and SJF and simulated the application of the eccentricity for the columns in the existing structures.

\subsection{Behaviour of the specimens under four-point bending}

Failure modes of the specimens tested under four-point bending are shown in Figure 9. Specimens SB, SF-B, SJ-B and SJF-B experienced initial cracks at the midspan segment of the specimen before reaching the ultimate flexural load. In general, the cracks were vertical flexural cracks, which started from the tension side and propagated upwards to the compression side within the midspan region of the specimens. The failure of Specimen S-B occurred by the rupture of the tensile steel bars. The failure of Specimen SF-B and Specimen SJF-B was characterized by the cracks between the CFRP strips on the tension side. Specimen SJ-B failed mainly by a wide crack and several small cracks, which developed from the tension side and propagated towards the compression side with the crushing of RPC on the compression side.

As can be observed from Figure 10, the yield load of Specimen S-B was $107 \mathrm{kN}$ and the corresponding yield deflection was $3.4 \mathrm{~mm}$. After the yield load, the flexural load increased gradually up to the ultimate flexural load of $148 \mathrm{kN}$. The energy absorption of Specimen S-B was $2173 \mathrm{kN} . \mathrm{mm}$ (Table 4).

The initial flexural stiffness of Specimens SF-B and S-B was similar. Specimen SF-B showed a slightly steeper hardening response than Specimen S-B up to the ultimate flexural load. The specimen failed suddenly due to the cracks between the CFRP strips on the tension side of the specimen. For 
Specimen SF-B, the yield flexural load was $23 \%$ higher than the yield flexural load of Specimen SB, and the ultimate flexural load was $24 \%$ higher than the ultimate flexural load of Specimen S-B. The energy absorption of Specimen SF-B was $84 \%$ higher than the energy absorption of Specimen S-B (Table 4).

The initial flexural stiffness of Specimen SJ-B was higher than the initial flexural stiffness of Specimens S-B and SF-B. The higher initial flexural stiffness of Specimen SJ-B was due to the circularisation of the cross-section with the RPC jacket. Specimen SJ-B achieved a yield flexural load of $268 \mathrm{kN}$ and an ultimate flexural load of $340 \mathrm{kN}$. Afterwards, a gradual softening response occurred up to the final failure. The yield flexural load of Specimen SJ-B was $150 \%$ higher than the yield flexural load of Specimen S-B. The ultimate flexural load of Specimen SJ-B was $130 \%$ higher than the ultimate flexural load of Specimen S-B. The increase in the yield and flexural loads of Specimen SJ-B compared to the yield and flexural loads of Specimen S-B was mainly due to the increase in the flexural stiffness by the RPC jacket. The energy absorption of Specimen SJ-B was 173\% higher than the energy absorption of Specimen S-B (Table 4).

The initial flexural stiffness of Specimen SJF-B was identical to that of Specimen SJ-B. This is because the wrapping with CFRP did not influence the initial flexural stiffness of the specimen. However, Specimen SJF-B showed higher flexural ultimate load and shorter post-ultimate softening response compared to Specimen SJ-B. The yield flexural load of Specimen SJF-B was $224 \%$ higher than the yield flexural load of Specimen S-B, and the ultimate flexural load of Specimen SJF-B was $170 \%$ higher than the ultimate flexural load of Specimen S-B. The energy absorption of Specimen SJF-B was $231 \%$ higher than the energy absorption of Specimen S-B (Table 4). The increase in the energy absorption of Specimen SJF-B compared to that of Specimen SJ-B was due to the confinement effect of CFRP wrapping.

It is noted that the increase in the flexural capacity for Specimens SJ-B and SJF-B compared to Specimen S-B was mainly due to the increase in the flexural stiffness of the specimens. However, 
Specimen SJF-B achieved more energy absorption than Specimen SJ-B due to the confinement effect of CFRP wrapping.

\subsection{Experimental axial load-bending moment interaction diagrams}

Figure 11 shows the axial load-bending moment interactions of the four groups of tested specimens. The first point in the axial load-bending moment interaction diagram represents the pure axial load. The second and the third points represent the axial loads and bending moments under $20 \mathrm{~mm}$ and 40 mm eccentric axial loads, respectively. The fourth point represents the pure bending moment capacity of the specimen. The bending moments of the specimens under eccentric axial loads were calculated by using Equation (1) and the bending moment of the specimen under four-point bending was calculated by using Equation (2).

$$
\begin{gathered}
M_{e}=P_{a} e+P_{a} \delta \\
M_{p}=\frac{P_{f} l}{6}
\end{gathered}
$$

where, $M_{e}$ is the bending moment due to the eccentric axial load, $P_{a}$ is the ultimate eccentric axial load, $e$ is the corresponding eccentricity, $\delta$ is the lateral deformation at the corresponding ultimate eccentric axial load, $M_{p}$ is the pure bending moment, $P_{f}$ is the ultimate flexural load and $l$ is the span length of the specimen which was $700 \mathrm{~mm}$ in this study.

It can be observed from Figure 11 that specimens of Groups SJ and SJF had significantly higher axial load-bending moment capacity compared to specimens of Groups S and SF. In addition, the specimens of Group SJF had greater axial load-bending moment capacity than the specimens of Group SJ. Under $20 \mathrm{~mm}$ eccentric axial load, the bending moments of Specimens SF-20, SJ-20 and SJF-20 were $131 \%, 328 \%$ and $419 \%$, respectively, higher than the bending moment of Specimen S20. Under the eccentric axial load of $40 \mathrm{~mm}$ eccentricity, the bending moments of Specimens SF-40, SJ-40 and SJF-40 were 59\%, 338\% and 423\%, respectively, higher than the bending moment of 
Specimen S-40. The bending moments of Specimens SF-B, SJ-B and SJF-B were 23\%, 129\% and $170 \%$, respectively, higher than the bending moment of Specimen S-B.

To generalize the results of this study, it is important to note that the confinement ratio, which is the ratio of the confinement pressure to the unconfined compressive strength for Group SF was 0.22. The radius of the corner of the specimens of Group SF was $13 \%$ of the side length of the square section. The ratio of the unconfined compressive strength of the RPC to the unconfined compressive strength of the NSC for Group SJ was 3.8. The RPC jacket thickness at the corner of the square section was $9.33 \%$ of the side length of the square section. Group SJ achieved greater yield and ultimate loads and energy absorption than Group SF under concentric axial load, eccentric axial loads and four-point bending. The ultimate load and energy absorption of Group SJF were greater than those of Group SJ under concentric axial load, eccentric axial loads and four-point bending.

Based on the above experimental results, it was found that the circularisation with RPC and wrapping with CFRP is more effective at strengthening square RC columns than only circularisation with RPC, achieving higher strength and higher energy absorption.

\section{Conclusions}

This experimental study proposed a new strengthening technique for square RC columns. The new strengthening technique included circularisation of the square RC column with RPC jacket then wrapping with CFRP. Based on the experimental results of this study, the following conclusions can be drawn:

(1) Under concentric axial load, eccentric axial loads and four-point bending the yield and ultimate load, as well as the energy absorption of square column specimens strengthened by the circularisation with RPC jacket, were significantly higher than the corresponding yield and ultimate load and energy absorption of the same square column specimens strengthened with only CFRP wrapping. 
(2) The experimental results of this study revealed that RPC can be used effectively as a shape modifier and a strengthening jacket for square RC columns.

(3) Wrapping the RPC jacketed specimens with CFRP increased the ultimate load and energy absorption of the specimens tested under concentric axial load, eccentric axial loads and fourpoint bending.

(4) The circularisation with RPC and wrapping with CFRP for the square RC columns increased significantly the initial axial stiffness and maximum axial stress of the columns.

(5) Wrapping the axially loaded RPC jacketed specimens with CFRP is recommended not only to enhance the axial load capacity and energy absorption but also to prevent the premature failure of the RPC jacket at the corners of the base specimen.

\section{Acknowledgements}

The authors would like to acknowledge the University of Wollongong, Australia for the financial support for this experimental study. The authors also acknowledge the Australasian (iron \& steel) Slag Association for the free supply of the silica fume. The first author acknowledges the full financial support for his $\mathrm{PhD}$ studies by the Iraqi Government and the Higher Committee for Education Development in Iraq. Lastly, sincere thanks to all technical staff in the laboratory of the School of Civil, Mining and Environmental Engineering, University of Wollongong for the technical support. Special and honest thanks to Technical Officer Mr. Ritchie McLean at the School of Civil, Mining and Environmental Engineering.

\section{References}

ACI (American Concrete Institute). (2017). Guide for the design and construction of externally bonded FRP systems for strengthening concrete structures. ACI: 440.2R-17, Farmington Hills, MI. 
AS (Australian Standards). (2007). Metallic materials tensile testing at ambient temperatures. $A S$ 1391-2007, Sydney, NSW, Australia.

AS (Australian Standards). (2009). Concrete Structures. AS 3600-2009, Sydney, NSW, Australia.

AS (Australian Standards). (2010). General purpose and blended cements. AS 3972-2010, Sydney, NSW, Australia.

AS (Australian Standards). (2014). Compressive strength tests - concrete, mortar and grout specimens. AS 1012.9-2014, Sydney, NSW, Australia.

AS (Australian Standards). (2014). Determination of indirect tensile strength of concrete cylinders. AS 1012.10-2014, Sydney, NSW, Australia.

ASA. (2018). Australasian (iron \& steel) Slag Association. Wollongong, NSW, Australia, 〈http://www.asa-inc.org.aul $>$

ASTM. (1997). Flexural Toughness and First-Crack Strength of Fibre-Reinforced Concrete (Using Beam With Third-Point Loading). ASTM C1018: 1997, West Conshohocken, PA.

ASTM. (2008). Standard test method for tensile properties of polymer matrix composite materials. ASTM D3039: 2008, West Conshohocken, PA.

ASTM. (2014). Standard Specification for Flow Table for use in Tests of Hydraulic Cement. ASTM C230-2014, West Conshohocken, PA.

BASF (2018). Master Glenium ${ }^{\circledR}$ SKY 8700-Technical Data Sheet. BASF-Australia, <www.BASF.cam.au> (Apr. 15, 2018).

Bank, L. C. (2006). Composites for construction: Structural design with FRP materials, Wiley, Hoboken, NJ.

Campione, G., Fossetti, M., Giacchino, C., \& Minafo, G. (2014). RC columns externally strengthened with RC jackets. Materials and Structures, 47(10), 1715-1728. 
Chang, T. B., Chen, B. T., Wang, J. J., \& Wu, C. S. (2009). Performance of Reactive Powder concrete (RPC) with different curing conditions and its retrofitting effects on concrete member, in Alexander et al. (eds), Concrete Repair, Rehabilitation and Retrofitting II, Taylor \& Francis Group, London, 1203-1208.

Hadi, M. N. S. (2009). Behaviour of eccentric loading of FRP confined fibre steel reinforced concrete columns. Construction and Building Materials, 23(2), 1102-1108.

Hadi, M. N. S., Khan, Q. S., \& Sheikh, M. N. (2016). Axial and flexural behaviour of unreinforced and FRP bar reinforced circular concrete filled FRP tube columns. Construction and Building Materials, 122(1), 43-53.

Hadi, M. N. S., Mai, A. D., \& Sheikh, M. N. (2018). Investigation on the behaviour of partial wrapping in comparison with full wrapping of square RC columns under different loading conditions. Construction and Building Materials, 168(1), 153-168.

Hadi, M. N. S., Pham, T. M., \& Lei, X. (2013). New method of strengthening reinforced concrete square columns by circularising and wrapping with fiber-reinforced polymer or steel straps. Journal of Composites for Construction, 17(2), 229-238.

Huynh, L., Foster, S. J., Valipour, H., \& Randall, R. (2015). High strength and reactive powder concrete columns subjected to impact: Experimental investigation. Construction and Building Materials, 78(1), 153-171.

Ju, Y., Jia, Y., Liu, H., \& Chen, J. (2007). Mesomechanism of Steel Fibre Reinforcement and Toughening of Reactive Powder Concrete. Science in China Series E: Technological Sciences, 50(6), 815-832.

Julio, E. S., Branco, F., \& Silva, VD. (2003). Structural rehabilitation of columns with reinforced concrete jacketing. Progress in Structural Engineering and Materials, 5(1), 29-37. 
Karbhari, V. M., \& Gao, Y. (1997). Composite jacketed concrete under uniaxial compressionVerification of simple design Equations. Journal of Materials in Civil Engineering, 9(4), 185 193.

Lam, L., \& Teng, J. (2003). Design-oriented stress-strain model for FRP-confined concrete in rectangular columns. Journal of Reinforced Plastics and Composites, 22(13), 1149-1186.

Lee, M. G., Wang, Y. C., \& Chiu, C. T. (2007). A Preliminary Study of Reactive Powder Concrete as a New Repair Material. Construction and Building Materials, 21(1), 182-189.

Malik, A. R., \& Foster, S. J. (2010). Carbon fiber-reinforced polymer confined reactive powder concrete columns-experimental investigation. ACI Structural Journal, 107(3), 263-271.

Minafo, G., \& Papia, M. (2016). Concrete softening effects on the axial capacity of RC jacketed circular columns. Engineering Structures, 128, 215-224.

Richard, P., \& Cheyrezy, M. (1995). Composition of Reactive Powder Concretes. Cement and Concrete Research, 25(7), 1501-1511.

Rodriguez, M., \& Park, R. (1991). Repair and strengthening of reinforced concrete buildings for seismic resistance. Earthquake Spectra, 7(3), 439-459.

SIMCOA (2018). Micro silica material safety data sheet, SIMCOA operations pty. ltd., <http://www.simcoa.com.au> (Apr. 15, 2018).

Sezen, H., \& Miller, E. A. (2011). Experimental Evaluation of Axial Behavior of Strengthened Circular Reinforced-Concrete Columns. Journal of Bridge Engineering, 16(2), 238-247.

Steel Wire Fibres (2018). Micro steel fibre WSF0213 III specifications. Ganzhou Daye Metallic Fibres Co.,Ltd, <http://www.gzdymf.com> (Apr. 15, 2018).

Takeuti, A. R., de Hanai, J. B., \& Mirmiran, A. (2008). Preloaded RC columns strengthened with high-strength concrete jackets under uniaxial compression. Materials and structures, 41(7), 1251-1262. 
Waghmare, S. P. B. (2011). Materials and jacketing technique for retrofitting of structures. International Journal of Advanced Engineering Research and Studies, 1(1), 15-19.

Wu, Y-F., Liu, T., \& Oehlers, D. (2006). Fundamental principles that govern retrofitting of reinforced concrete columns by steel and FRP jacketing. Advances in Structural Engineering, 9(4), 507533.

Yan, Z., \& Pantelides, C. P. (2011). Concrete column shape modification with FRP shells and expansive cement concrete. Construction and Building Materials, 25(1), 396-405. 


\section{List of Tables:}

Table 1. Test matrix

Table 2. Experimental results of specimens tested under concentric axial load

Table 3. Experimental results of specimens tested under $20 \mathrm{~mm}$ and $40 \mathrm{~mm}$ eccentric axial load

Table 4. Experimental results of specimens tested under four-point bending 


\section{List of Figures:}

Figure 1. Cross-sections of the specimens: (a) Group S, (b) Group SF, (c) Group SJ, and (d) Group SJF

Figure 2. Preparation of specimens: (a) formwork and reinforcement of reference specimen, (b) formwork of jacketed specimen, and (c) jacketed specimen after casting

Figure 3. Test setup of eccentrically loaded specimen

Figure 4. Failure modes of the specimens tested under concentric axial load

Figure 5. Axial load-axial deformation responses of the specimens tested under concentric axial load Figure 6. Axial stress-axial strain responses of the specimens tested under concentric axial load Figure 7. Failure modes of the specimens tested under eccentric axial load: (a) eccentricity $=20 \mathrm{~mm}$, and (b) eccentricity $=40 \mathrm{~mm}$

Figure 8. Axial load-axial deformation and axial load-lateral deformation responses of the specimens tested under eccentric axial load: (a) eccentricity $=20 \mathrm{~mm}$, and (b) eccentricity $=40 \mathrm{~mm}$ Figure 9. Failure modes of the specimens tested under four-point bending Figure 10. Flexural load-midspan deflection responses of the specimens tested under four-point bending

Figure 11. Experimental axial load-bending moment interaction diagrams 
Table 1. Test matrix

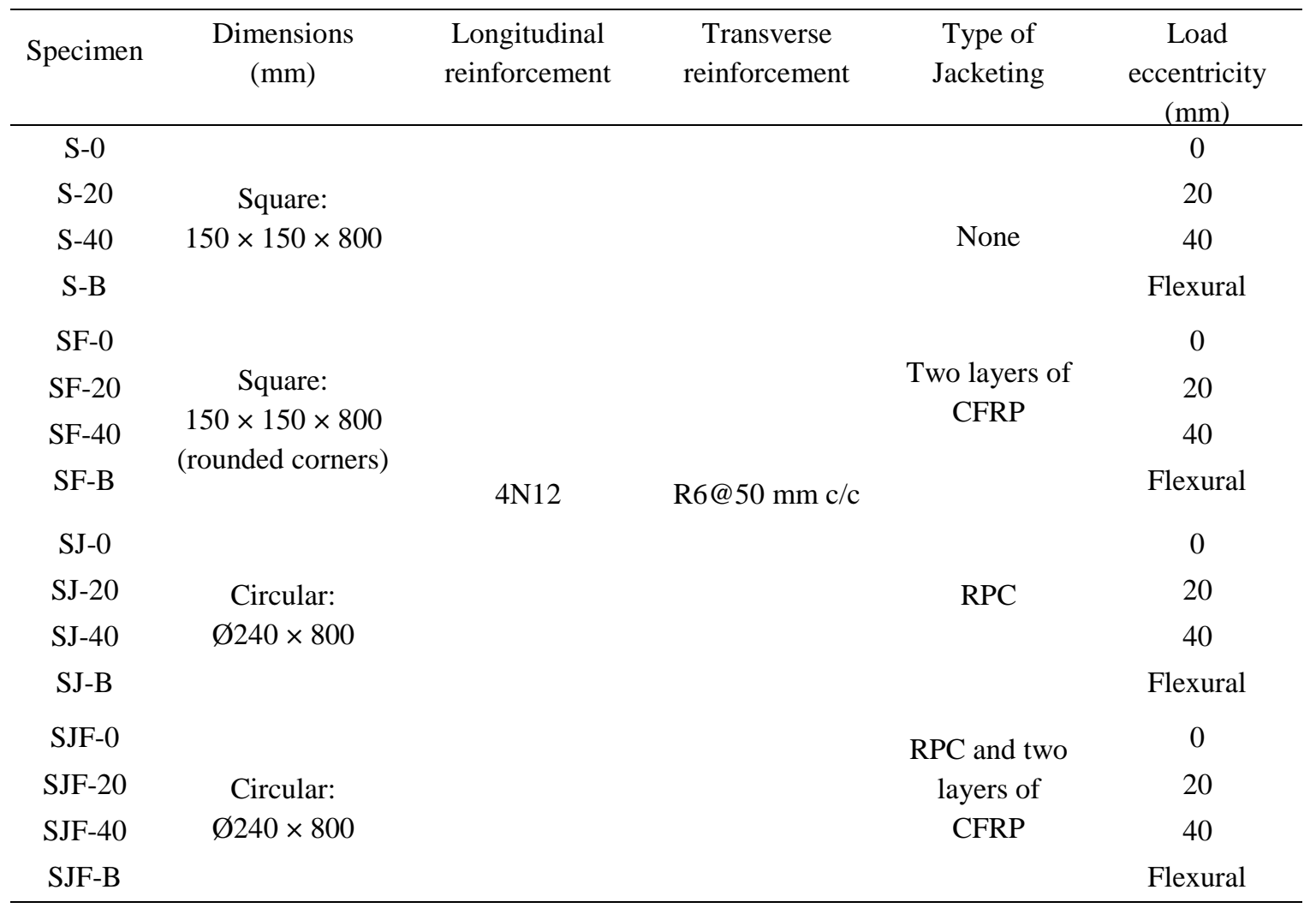


Table 2. Experimental results of specimens tested under concentric axial load

\begin{tabular}{ccccc}
\hline Specimen & S-0 & SF-0 & SJ-0 & SJF-0 \\
\hline Yield axial load (kN) & 666 & 855 & 2652 & 3018 \\
$\begin{array}{c}\text { Axial deformation at yield } \\
\text { axial load (mm) }\end{array}$ & 2.2 & 4 & 3 & 3.6 \\
$\begin{array}{c}\text { Ultimate axial load (kN) } \\
\text { Axial deformation at }\end{array}$ & 798 & 1462 & 2892 & 3641 \\
ultimate axial load (mm) & 3.9 & 30.5 & 3.7 & 6.3 \\
Energy absorption (kN.mm) & 4000 & 10343 & 13569 & 22695 \\
\hline
\end{tabular}


Table 3. Experimental results of specimens tested under $20 \mathrm{~mm}$ and $40 \mathrm{~mm}$ eccentric axial load

\begin{tabular}{|c|c|c|c|c|c|c|c|c|}
\hline Specimen & $\mathrm{S}-20$ & SF-20 & SJ-20 & SJF-20 & $\mathrm{S}-40$ & SF-40 & $\mathrm{SJ}-40$ & SJF-40 \\
\hline Yield axial load $(\mathrm{kN})$ & 397 & 595 & 1915 & 2227 & 297 & 362 & 1462 & 1670 \\
\hline $\begin{array}{l}\text { Axial deformation at yield } \\
\text { axial load }(\mathrm{mm})\end{array}$ & 2.3 & 3.3 & 3.7 & 4.6 & 2.7 & 3.3 & 3.3 & 3.8 \\
\hline Ultimate axial load $(\mathrm{kN})$ & 418 & 650 & 2054 & 2398 & 329 & 429 & 1549 & 1814 \\
\hline $\begin{array}{c}\text { Axial deformation at } \\
\text { ultimate axial load (mm) }\end{array}$ & 2.8 & 9.1 & 4.4 & 5.5 & 3.8 & 8.9 & 3.7 & 5.1 \\
\hline $\begin{array}{l}\text { Lateral deformation at } \\
\text { ultimate axial load (mm) }\end{array}$ & 6 & 18.5 & 2.5 & 3.4 & 6.6 & 16.7 & 3.2 & 4.1 \\
\hline $\begin{array}{l}\text { Energy absorption } \\
\quad(\mathrm{kN} . \mathrm{mm})\end{array}$ & 2207 & 5277 & 8176 & 19036 & 2125 & 2930 & 5609 & 14401 \\
\hline
\end{tabular}


Table 4. Experimental results of specimens tested under four-point bending

\begin{tabular}{ccccc}
\hline Specimen & S-B & SF-B & SJ-B & SJF-B \\
\hline Yield flexural load (kN) & 107 & 132 & 268 & 347 \\
$\begin{array}{c}\text { Deflection at yield flexural } \\
\text { load (mm) }\end{array}$ & 3.4 & 5.1 & 4.1 & 4.7 \\
$\begin{array}{c}\text { Ultimate flexural load (kN) } \\
\text { Deflection at ultimate }\end{array}$ & 148 & 183 & 340 & 400 \\
flexural load (mm) & 34.7 & 37.8 & 9.2 & 16.7 \\
Energy absorption (kN.mm) & 2173 & 3999 & 5944 & 7203 \\
\hline
\end{tabular}




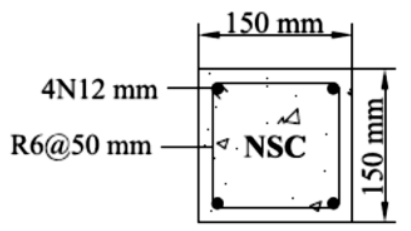

(a)

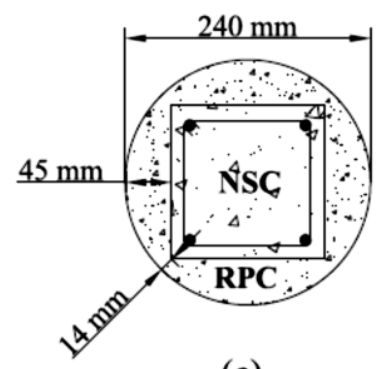

(c)

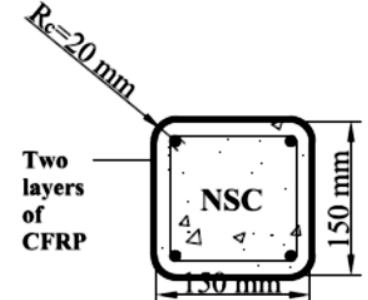

(b)

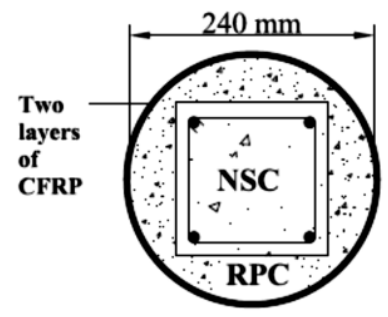

(d)

Figure 1. Cross-sections of the specimens: (a) Group S, (b) Group SF, (c) Group SJ, and (d) Group SJF 


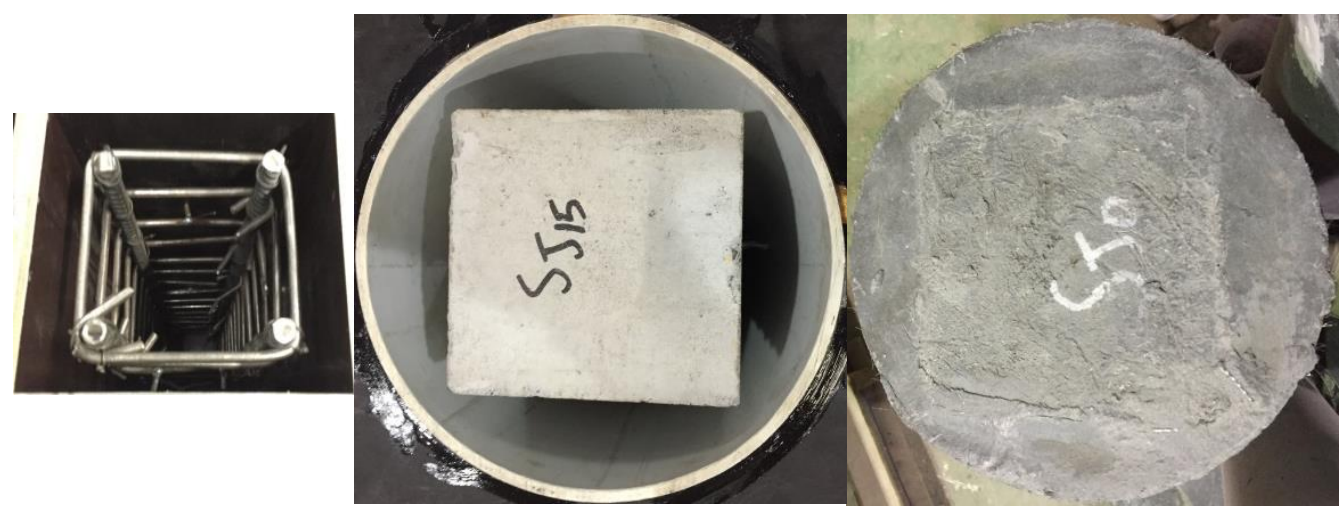

(a)

(b)

(c)

Figure 2. Preparation of specimens: (a) formwork and reinforcement of reference specimen, (b) formwork of jacketed specimen, and (c) jacketed specimen after casting 


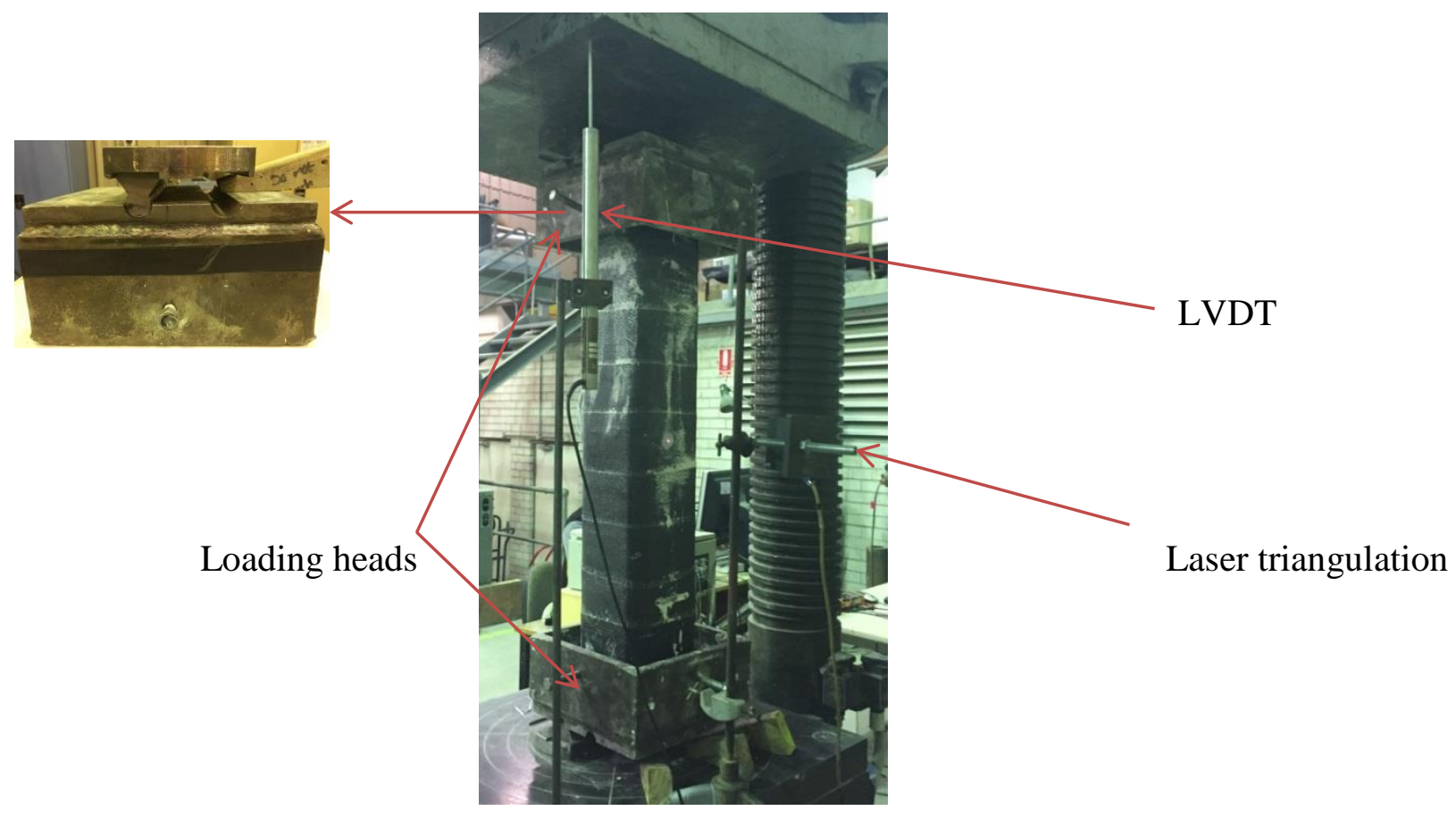

Figure 3. Test setup of eccentrically loaded specimen 


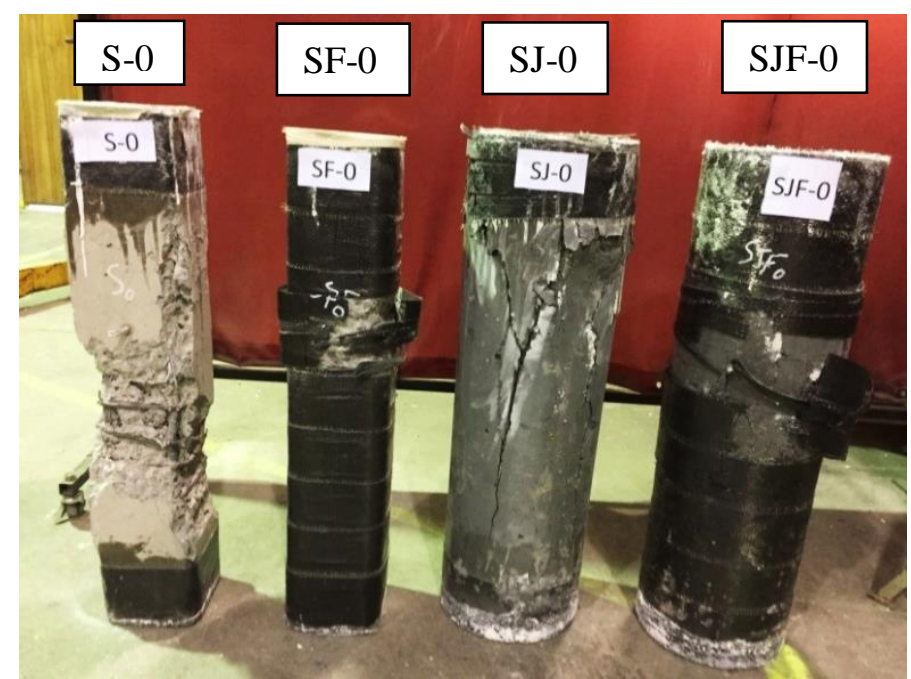

Figure 4. Failure modes of the specimens tested under concentric axial load 


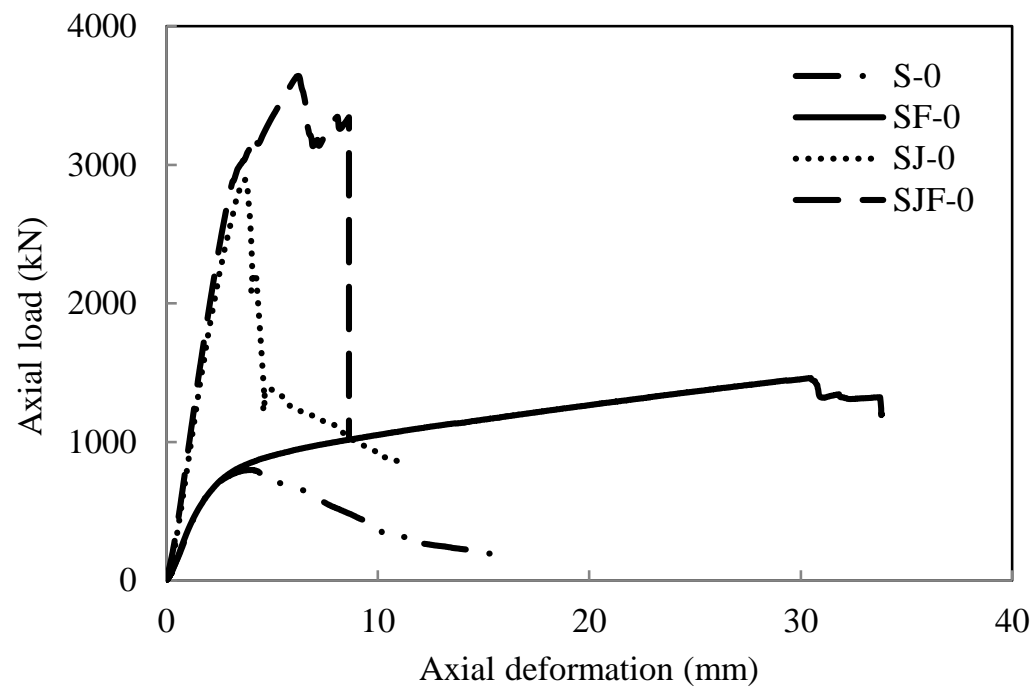

Figure 5. Axial load-axial deformation responses of the specimens tested under concentric axial load 


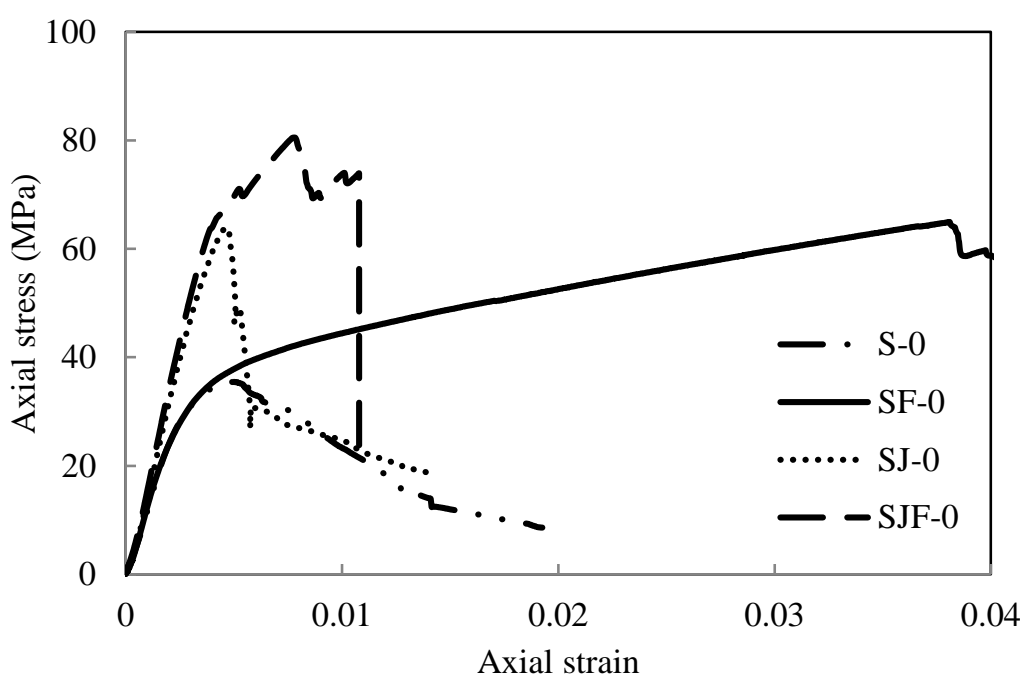

Figure 6. Axial stress-axial strain responses of the specimens tested under concentric axial load 


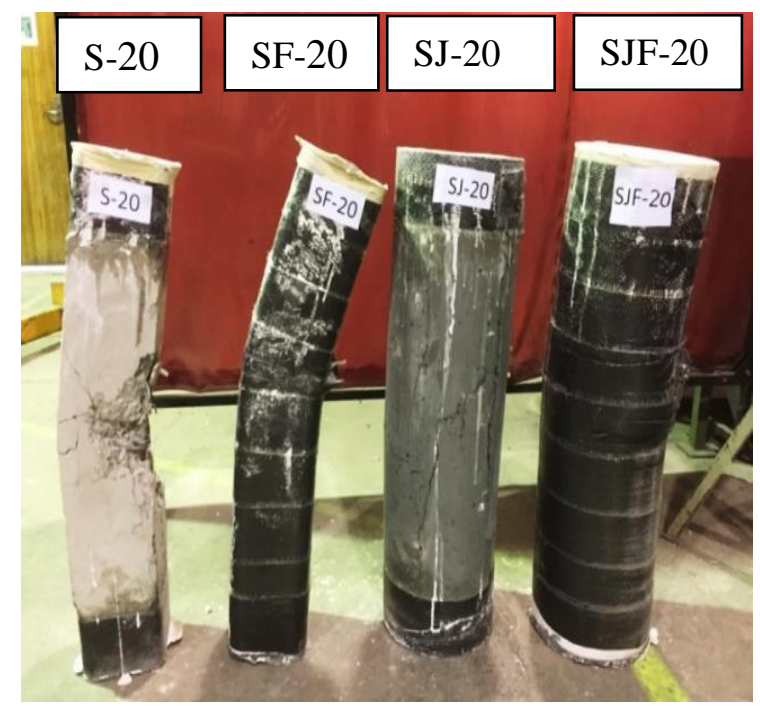

(a)

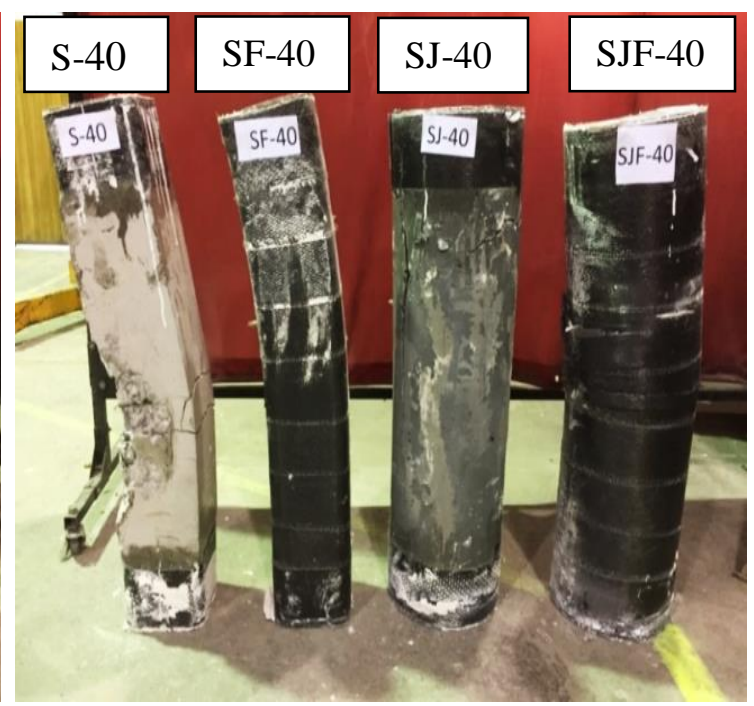

(b)

Figure 7. Failure modes of the specimens tested under eccentric axial load: (a) eccentricity $=20 \mathrm{~mm}$, and (b) eccentricity $=40 \mathrm{~mm}$ 

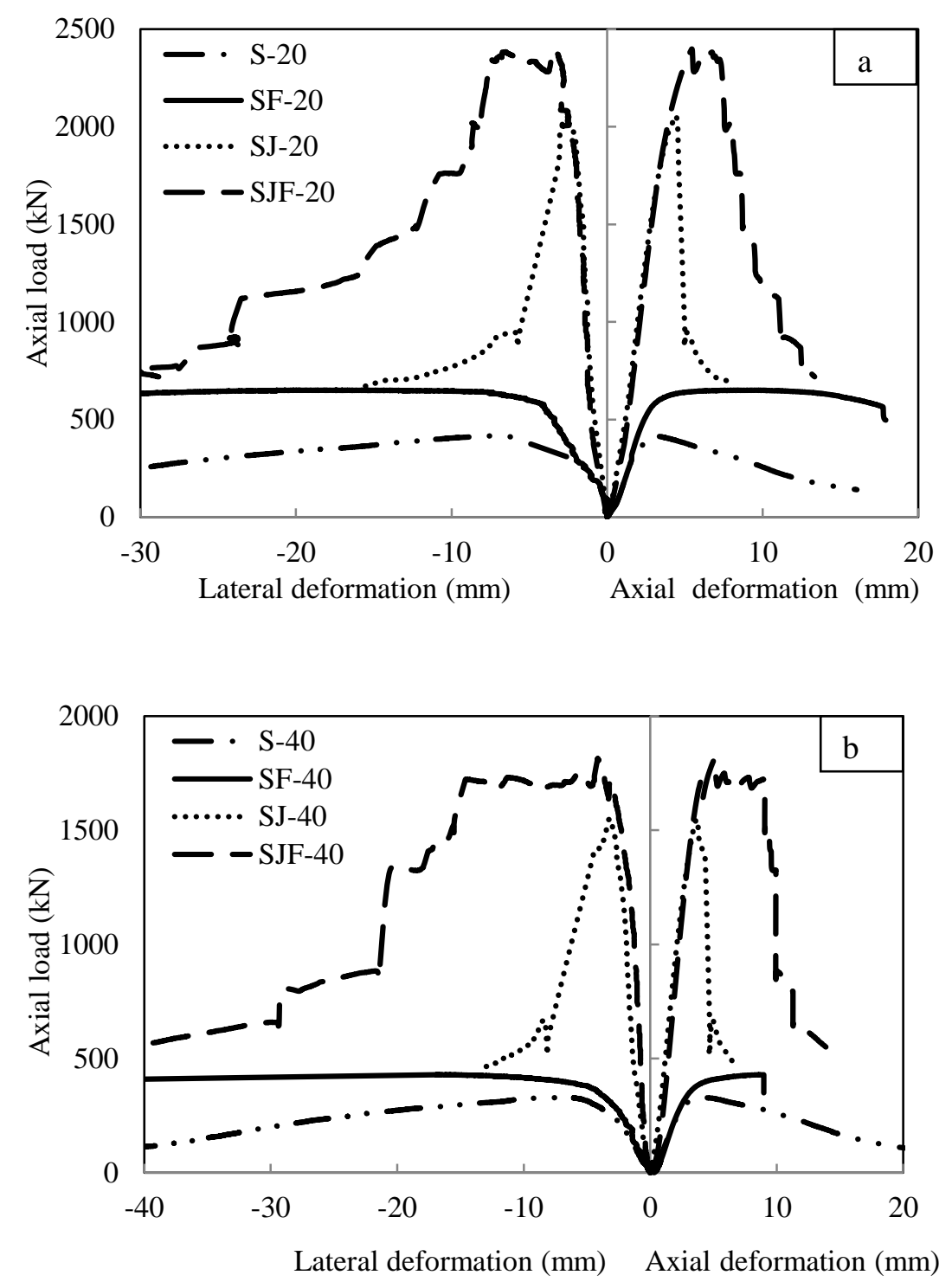

Figure 8. Axial load-axial deformation and axial load-lateral deformation responses of the specimens tested under eccentric axial load: (a) eccentricity $=20 \mathrm{~mm}$, and (b) eccentricity $=40 \mathrm{~mm}$ 


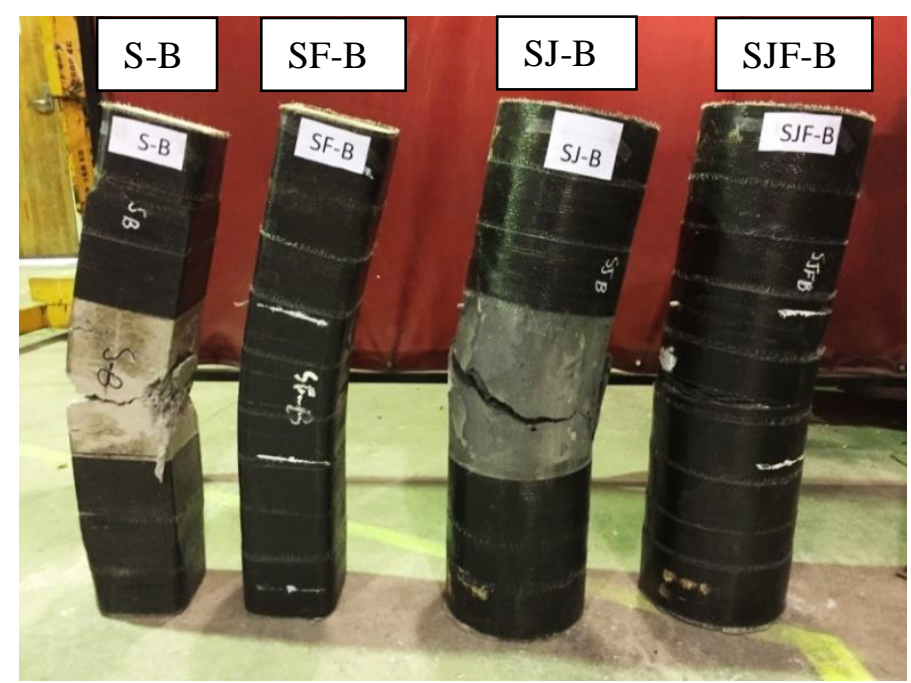

Figure 9. Failure modes of the specimens tested under four-point bending 


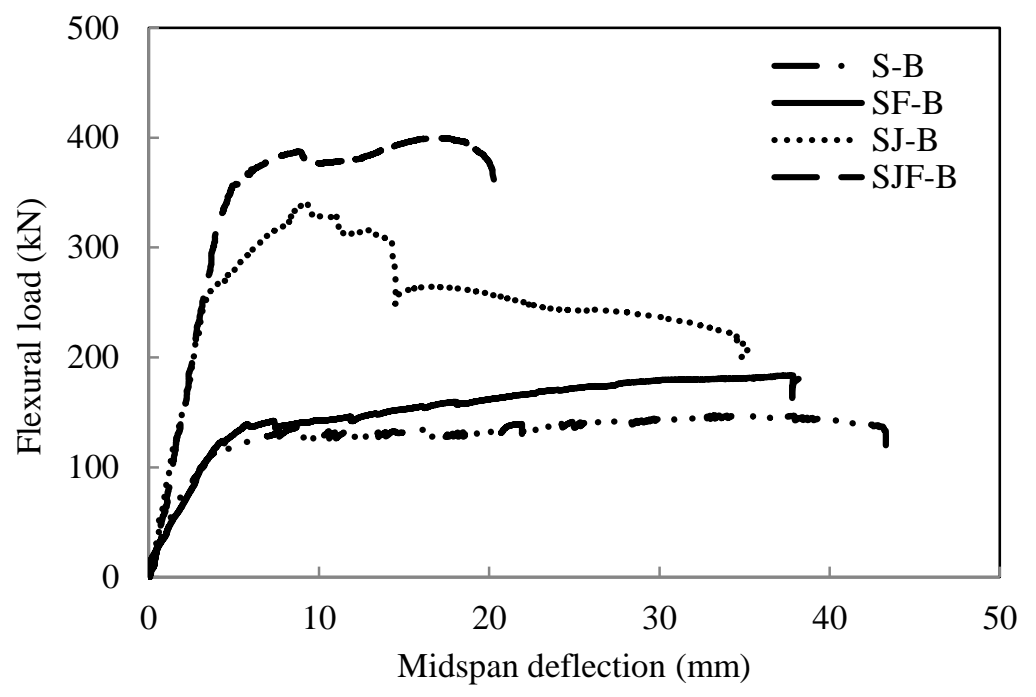

Figure 10. Flexural load-midspan deflection responses of the specimens tested under four-point bending 


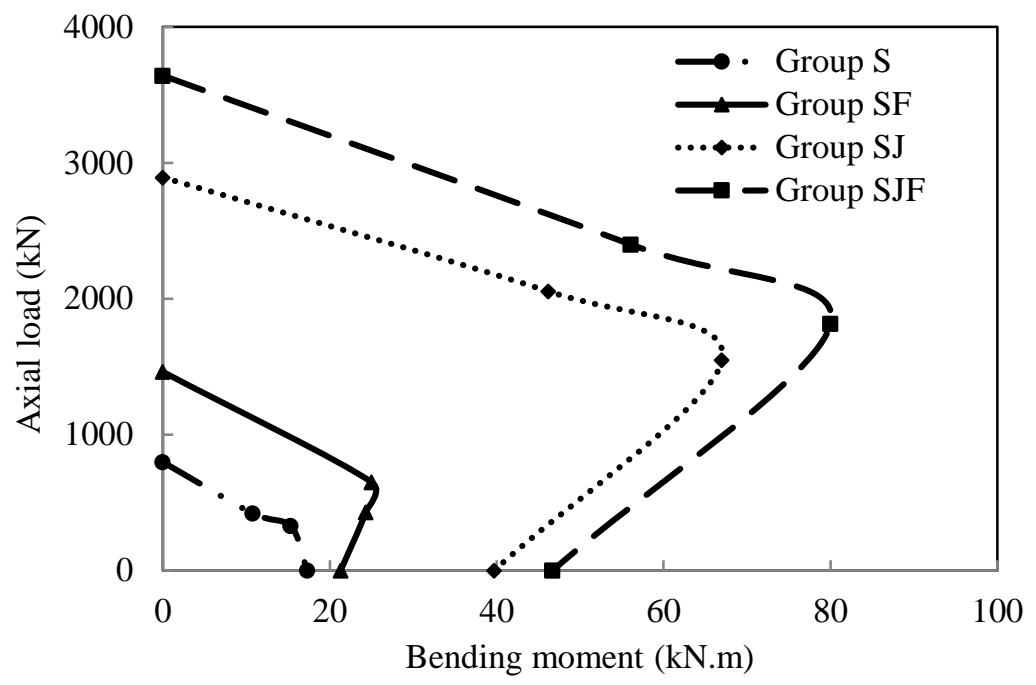

Figure 11. Experimental axial load-bending moment interaction diagrams 